\title{
Knowledge of School Teachers Regarding Dental Trauma Before and After the Use of Flash Cards
}

\author{
Manya Suresh ${ }^{1}$ and Mebin George Mathew ${ }^{2}$ \\ ${ }^{1}$ Saveetha Dental College and Hospitals, Saveetha Institute of Medical \\ and Technical Sciences, Saveetha University, Chennai - 600077, India \\ ${ }^{2}$ Senior Lecturer, Department of Pedodontics and Preventive Dentistry, Saveetha Dental College \\ and Hospitals, Saveetha Institute of Medical and Technical Sciences, Chennai - 600077, India
}

\section{ABSTRACT}

Traumatic dental injuries (TDIs) are very common in childhood. Majority of TDIs occur at schools. The prognosis of TDIs to a great extent is dependent on emergency measures taken at the site of the accident. Hence, it is of paramount importance to assess the knowledge of people present at the site of the accident that generally includes parents, teachers, and sports coaches.A cross-sectional survey was conducted on 100 school teachers using a close- ended questionnaire. The questionnaire had eight questions regarding management of dental trauma.The questionnaire was administered again after the use of flash cards and the responses were compared. The data was statistically analysed.The overall knowledge of school teachers regarding management of TDIs was not found to be satisfactory before the use of flash cards. It was observed that most of the teachers were unaware of the steps to be taken on their part to minimize complications and improve prognosis.Despite the lack of knowledge and awareness regarding management of dental trauma initially, they had a good attitude towards management of dental trauma and its education after the use of flash cards.

\section{KEY WORDS: AVULSION;KNOWLEDGE;MEDIUM;SCHOOL,TEACHERS.}

\section{INTRODUCTION}

Physical activity is a basic need for the growth of children. During these physical activities, injuries to the face are one of the most common risks associated with it. Trauma to both primary and permanent dentition continues as a frequent dental problem. As long as young children remain active, trauma to both primary and permanent dentition continues to be a frequent dental

\section{ARTICLE INFORMATION}

*Corresponding Author: mebingeorgem.sdc@saveetha.com Received 12th June 2020 Accepted after revision 2nd August 2020 Print ISSN: 0974-6455 Online ISSN: 2321-4007 CODEN: BBRCBA

Thomson Reuters ISI Web of Science Clarivate Analytics USA and Crossref Indexed Journal

\section{Clarivate
Analytics}

NAAS Journal Score 2020 (4.31) SJIF: 2020 (7.728)

A Society of Science and Nature Publication,

Bhopal India 2020. All rights reserved.

Online Contents Available at: http//www.bbrc.in/

Doi: http://dx.doi.org/10.21786/bbrc/13.7/59
problem.(Andreasen, 1985) It is known that the majority of dental injuries are seen in children between ages of 8 and 11 years. The prevalence of dental injuries is 60\% out of which over $48 \%$ involve maxillary teeth. Over $16 \%$ was in the school environment and 19\% of the injury due to fall.(Mohandas and Chandan, 2009).

An untreated and unsightly fracture of an anterior tooth can affect the behavior of a child, his progress in school, and can have more impact on their daily living.(Kumar et al., 2011). Epidemiological studies indicate that dental trauma is a significant problem in young people and that in the near future, the incidence of trauma will exceed that of dental caries and periodontal disease in the young population ((Neena et al., 2017), (Nagaveni, Yadav and Poornima, 2017), (Nagaveni, Poornima and Valsan, 2018). 
Traumatic dental injuries seen to be a serious dental public health problem among children in deprived areas. Thus there is an urgent need to collect the local data on dental injuries in order to obtain a more comprehensive picture of the dental health.(Juneja, Kulkarni and Raje, 2018). The main cause of TDI among school-age children are unprecedented falls in schools. It has been previously reported that approximately 50\% of schoolchildren have experienced a TDI prior to graduation (Ravn, 1974). Therefore, it is highly likely that first aid would be provided by teachers and other school staff.(Awad et al., 2017)Immediate care is particularly important for the avulsed permanent tooth as the prognosis stays high as long as the replantation takes place within 30 minutes after avulsion. The prognosis of the avulsed tooth depends on the viability of periodontal ligament remaining on the root surface (Lieger et al., 2009).

The role of school teachers in the prevention of traumatic dental injuries is a topic that has received a great deal of attention in recent years (Pani et al., 2014). Most of the studies conducted in different regions of the world have demonstrated that teachers' knowledge about traumatic dental injuries is inadequate.(Chandukutty et al., 2017) Flashcards exercise the mental process of active recall: given a prompt (the question), one produces the answer. They are a classic study tool one among the better practices through which our brains learn most effectively. Not only do they help learners memorize facts quickly, they also enable long-term retention of information in the human brain. Especially when it comes to reviewing concepts, nothing comes close to the effectiveness of flashcards. (What are Flashcards and Why They Are a Good Tool for Mobile Learning? - Disprz, 2018)

Our department is passionate about child care, we have published numerous high quality articles in this domain over the past 3 years (Govindaraju, Jeevanandan and Subramanian, 2017a, 2017b; Panchal, Gurunathan and Shanmugaavel, 2017; Ravikumar, Jeevanandan and Subramanian, 2017; Jeevanandan and Govindaraju, 2018; Nair et al., 2018; Ravikumar et al., 2018, 2019; Ravindra et al., 2018, 2019; Subramanyam et al., 2018; Vishnu Prasad et al., 2018; Jeevanandan, Ganesh and Arthilakshmi, 2019; Ramadurai et al., 2019; Ramakrishnan, Dhanalakshmi and Subramanian, 2019; Veerale Panchal, Jeevanandan and Subramanian, 2019; Vignesh et al., 2019; V. Panchal, Jeevanandan and Subramanian, 2019; Samuel, Acharya and Rao, 2020). With this inspiration we planned to pursue research on Knowledge of school teachers regarding dental trauma before and after the use of flash cards. In order to contribute to the effective strategies of creating awareness of traumatic dental injuries among school teachers, this study was conducted.

\section{MATERIAL AND METHODS}

A cross sectional survey of school teachers working in private and government schools of Chennai, India, was carried out to assess knowledge of management of dental trauma among them. A multistage sampling was adopted for selection of school teachers. Private and government schools were chosen randomly. In the second stage, all school teachers who gave consent to participate in the survey were included to make the final sample of 100 participants. A questionnaire containing eight questions was used in the study. The questionnaire consisted of questions regarding management of dental trauma.To help the participants make prompt decisions, they were given multiple choices.

This questionnaire was pretested on a sample of ten teachers who were later on excluded from the study. While they were filling up the questionnaire, a few questions were asked so that it could be confirmed if they understood the questions in the questionnaire. Any confusion or difficulty in comprehension so highlighted was rectified instantly. The nature and purpose of the study were explained to the teachers in their preferred language. Its voluntary nature was emphasized and strict confidentiality was assured. Two pre trained investigators were available throughout to make any required clarifications to the participants.Filled questionnaires were collected on the same day.

Figure 1: Pie chart representing the gender distribution of teachers that took part in this study more number of females took part in the study.

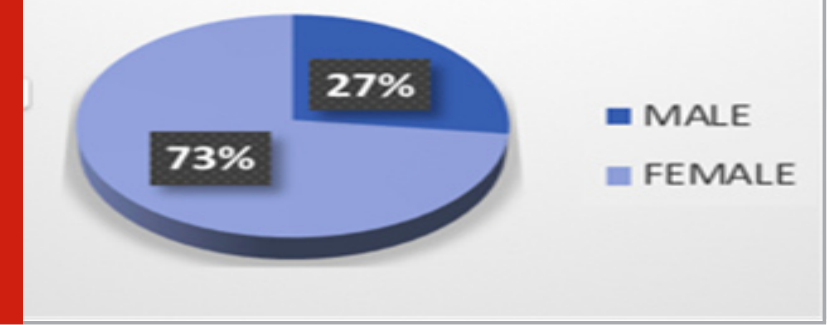

Figure 2: Bar chart shows the different sectors of work of teachers who took part in the study. $\mathrm{X}$ axis represents the sectors and $\mathrm{Y}$ axis shows the frequency of teachers who took part.There were more teachers from private sectors

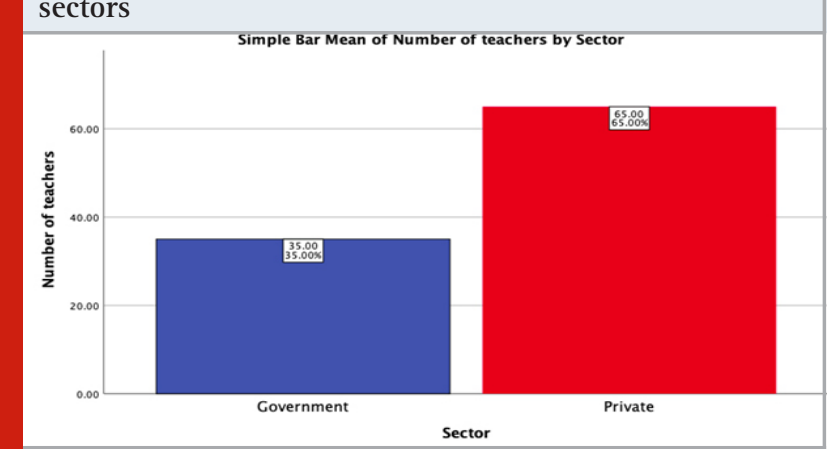

RESULTS AND DISCUSSION

A total of 100 school teachers took the questionnaire. Most of them were women (73\%), under 50 years of age (70.1\%)[ Figure 1]. 65\% of the teachers belonged to the 
private sector and 35\% belonged to the government sector[ Figure 2].30 \% of the teacher that took part in the study were from primary schools, $45 \%$ from secondary schools and 25\% from higher secondary schools[ Figure 3]. They were also sorted into groups based on their age [ Figure 4].Majority of them had not received any first aid training (88.\%) and had not witnessed any dental trauma accidents (92\%)[ Table 1].

Table 1 . Shows the responses of the questions asked to teachers before administration of the questionnaire.

Silo Personald details

Yes No

\begin{tabular}{|c|c|}
\hline 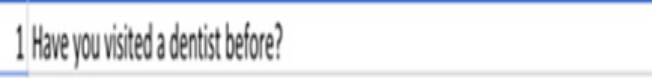 & 8218 \\
\hline 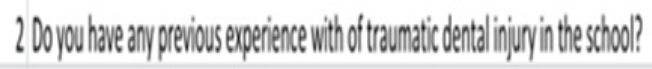 & $8 \%$ \\
\hline 3 Hove jou been giventraining on firstad betóre? & 1288 \\
\hline 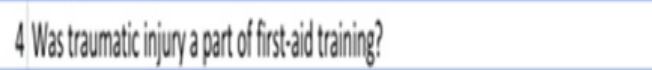 & 3 \\
\hline
\end{tabular}

The questionnaire was distributed among the teachers, each question had multiple choices and each answer was given a score if they had the ideal answer their score would be 2,if it was an acceptable answer it would be 1 and if it was the incorrect answer the score would be 0 . The questionnaire was administered again after the use of flash cards to increase the teachers knowledge on dental trauma. This time the scores were calculated again based on the same above mentioned criteria. The scores were then statistically analyzed and were given their $\mathrm{p}$ value.

It was observed that 56.6\% school teachers could correctly identify the damaged front tooth in a 9-yearold child as a permanent tooth. A significant association was found between previous first aid training received, service span, and question regarding identification of tooth. Most of the respondents $94.43 \%$ considered dental trauma an emergency situation. Majority of them 60.99\% possessed the knowledge of how to correctly manage a fractured tooth after the use of flash cards.In the case of an avulsed tooth falling to the ground, only 52\% school teachers responded that they would look for the lost tooth, and among them, $72.76 \%$ would clean it gently with water or some liquid whereas $10.84 \%$ would not clean the tooth and put it directly back into the socket. Regarding cleaning of dirty avulsed teeth, $42.86 \%$ male school teachers reported that they would look for the tooth and wash it with tap water. Moreover, among female teachers, 90\% reported that they would look for the lost tooth and put it back into the socket. Regarding cleaning of that tooth, $79.57 \%$ female teachers knew the correct method of cleaning the tooth.

A lesser number of school teachers $-15.17 \%$ were aware of the correct solution to clean a dirty avulsed tooth with. Most-31.58\% of them preferred an antiseptic solution to clean a dirty avulsed tooth. Significant association was found between previous first aid training, history of witnessing trauma, and question regarding solution used to clean a dirty avulsed tooth. Majority $-78.33 \%$ of school teachers were in favor of seeking professional help immediately in case of dental trauma. A large proportion of the participants $-93.18 \%$ were unaware of the medium to store avulsed tooth in, till the use of flash cards. Most of them preferred to store the tooth in tissue paper (58.51\%), filtered water (27.86\%), tap water (6.81\%), milk (3.72\%), or the child's mouth (3.10\%). A significant association was found between previous first aid training received and the question regarding mode of transport of avulsed tooth the dentist. Teachers after using the flash cards opted for milk (83.33\%) whereas teachers before the use of flash cards opted for paper tissue (58.51\%).

A large number of them did think that tetanus should be administered to the child after trauma only after the use of flash cards [ Table 2]. A significant number of school teachers were not satisfied with their knowledge regarding the emergency of dental trauma and most of them were willing to receive a short training regarding the emergency of dental trauma. The main objective of replanting an avulsed tooth is to retain it in its socket to maintain the patient's esthetic appearance and occlusal function and also to prevent root resorption(Rao, Kommula and Tummala, 2014). Storage media such as Hank's balanced salt solution and milk were considered to be the best examples of osmolality-balanced media for storing an avulsed tooth.(Andersson et al., 2012) Natural products such as coconut water, propolis, and green tea have been used and showed their ability to maintain the viability of periodontal ligament cells of an avulsed teeth.(Jain, Dasar and Nagarajappa, 2015) Milk is usually available at home or in grocery where one has easy accessibility in case of trauma.

Table 2. Shows the responses to the questions asked to the teachers before and after the use of flash cards. The data was statistically significant. (P value $<0.001$ ).

\begin{tabular}{|c|c|c|c|c|c|c|c|}
\hline & \multicolumn{3}{|c|}{ BEFORE } & \multicolumn{3}{|c|}{ AFTER } & \multirow[b]{2}{*}{ Pvalue } \\
\hline & 0 & 1 & 2 & 0 & 1 & 2 & \\
\hline $\begin{array}{l}\text { What is the best way to manage fractured } \\
\text { tooth? }\end{array}$ & 35 & 25 & 40 & 1 & 18 & 81 & 0.001 \\
\hline $\begin{array}{l}\text { If a tooth is loose due to trauma, what should } \\
\text { be done? }\end{array}$ & 30 & 27 & 43 & 3 & 7 & 90 & 0.001 \\
\hline $\begin{array}{l}\text { Do you think you can put the tooth completely } \\
\text { back in place ? }\end{array}$ & 94 & 0 & 6 & 0 & 0 & 100 & 0.001 \\
\hline $\begin{array}{c}\text { How will you hold a tooth that was knocked } \\
\text { out? }\end{array}$ & 95 & 0 & 5 & 5 & 5 & 95 & 0.001 \\
\hline How will you carry the knocked out tooth? & 90 & 5 & 5 & 0 & 4 & 96 & 0.001 \\
\hline $\begin{array}{l}\text { Where will you go for treatment of knocked } \\
\text { teeth? }\end{array}$ & 94 & 3 & 3 & 0 & 3 & 97 & 0.001 \\
\hline $\begin{array}{l}\text { Do you think tetanus injection is required after } \\
\text { a traumatic injury? }\end{array}$ & 56 & 9 & 35 & 5 & 10 & 85 & 0.001 \\
\hline $\begin{array}{l}\text { How urgently will you seek treatment for an } \\
\text { injured tooth? }\end{array}$ & 73 & 7 & 20 & 5 & 4 & 91 & 0.001 \\
\hline
\end{tabular}

The use of milk as a storage medium of the avulsed tooth has been reported to preserve the viability of periodontal ligament cells for up to $60 \mathrm{~min}$ at room temperature, and if refrigerated, it will preserve the tooth for an additional 45 min.(Blomlöf, Lindskog and Hammarström, 1981) In the current study, very few teachers gave a proper response regarding transportation medium of the avulsed tooth before the use of flash cards. The prognostic outcome of replanting an avulsed tooth depends on 
appropriate management immediately after the trauma. The main prognostic factors for better outcome of replanting the avulsed tooth are minimal extraoral time, appropriate transporting medium with minimal damage to root surface, and periodontal ligament.(Alzahrani, Almaqboul and Others, 2019; Nagaveni, Poornima and Bajaj, 2019; Mebin George Mathew et al., 2020; Nagaveni, Poornima and Mathew, 2020).Significant difference in the knowledge of dental trauma among the teachers was found before and after the use of flash cards $(\mathrm{P}=0.001)$.

Figure 3: Bar chart shows the different types of schools of teachers who took part in the study.X axis represents the types of schools and $\mathrm{Y}$ axis shows the frequency of teachers who took part.There were more teachers from secondary schools

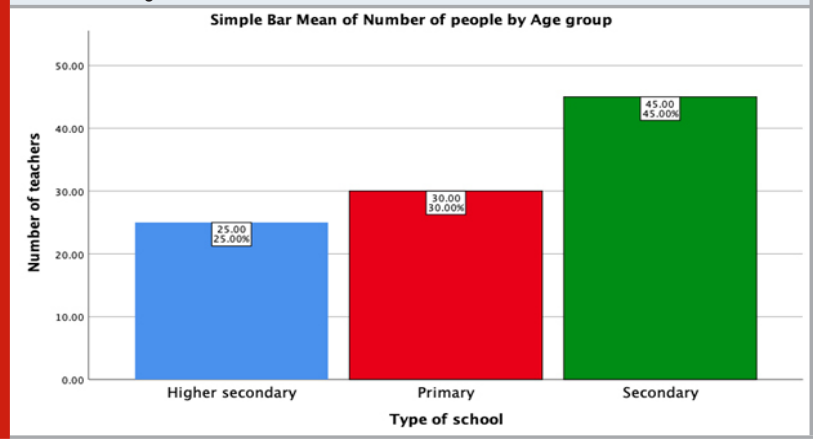

Figure 4: Bar chart shows the age group of teachers who took part in the study.X axis represents the age groups and $Y$ axis shows the frequency of teachers who took part.There were more teachers from the 20-30 year age group.

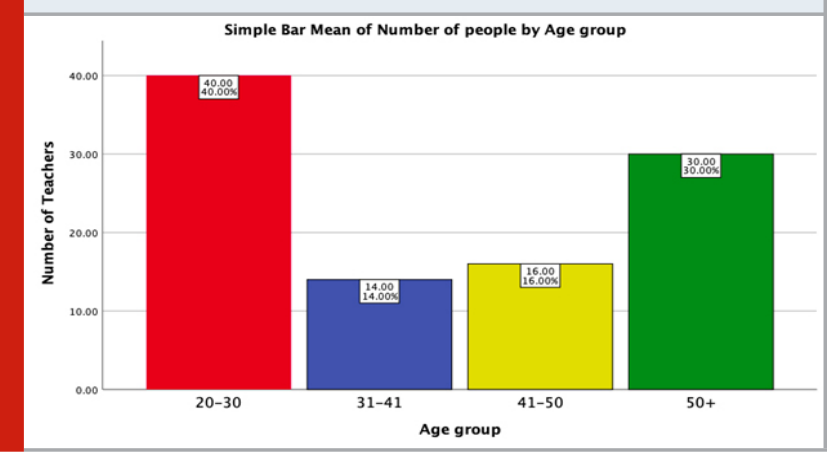

Children spend more time at school than at any other location outside the home; while at school they are involved in various physical activities that expose them to the risk of dental trauma. Thus, the school environment is a suitable place to promote oral healthrelated campaigns targeting the welfare of children. School teachers are the most likely people to connect with children soon after a traumatic incident, and it is their knowledge and understanding of emergency procedures that ensure the best prognosis for the clinical treatment provided by the dentist. Consequently, school staff are key strategic vectors for imparting knowledge and awareness of TDIs(Al-Sehaibany et al., 2018)
Flashcards engage the ability to think. The majority of this generation learns best by seeing the information in an example format. People of all ages are far more likely to remember visuals rather than words ((Mathew and Soni, 2019; M. G. Mathew et al., 2020). This technique will help increase their understanding of dental trauma and give them experience in the right direction ((Mathew, Roopa and Soni, 2020). The results of this study may help in making strategic plans to enhance the school teachers knowledge about TDIs .Flashcards can be implemented in their training to help in the better management of TDIs.

\section{CONCLUSION}

The results of this study shows that a significant number of school teachers had very little knowledge regarding the emergency of dental trauma before the use of flash cards and most of them were willing to receive a short training regarding the emergency of dental trauma.After the use of flash cards their knowledge on dental trauma had significantly increased .

\section{ACKNOWLEDGEMENTS}

The authors would like to acknowledge the help and support rendered by the department of Pedodontics and also the management of Saveetha Dental College and hospitals for their constant assistance with the research.

Conflict of Interest: None declared

\section{REFERENCES}

Al-Sehaibany, F. S. et al. (2018) 'Elementary school staff knowledge about management of traumatic dental injuries', Clinical, cosmetic and investigational dentistry, 10, pp. 189-194.

Alzahrani, M. S., Almaqboul, F. A. and Others (2019) 'Parents' awareness and attitude toward urgent management of avulsed permanent tooth in AL-Baha city', Saudi Endodontic Journal. Medknow Publications, 9(2), p. 82.

Andersson, L. et al. (2012) 'International Association of Dental Traumatology guidelines for the management of traumatic dental injuries: 2. Avulsion of permanent teeth', Dental traumatology: official publication of International Association for Dental Traumatology, 28(2), pp. 88-96.

Andreasen, J. 0. (1985) 'Challenges in clinical dental traumatology', Endodontics \& dental traumatology, 1(2), pp. 45-55.

Awad, M. A. et al. (2017) 'Assessment of Elementary School Teachers' Level of Knowledge and Attitude regarding Traumatic Dental Injuries in the United Arab Emirates', International Journal of Dentistry, pp. 1-7. doi: 10.1155/2017/1025324.

Blomlöf, L., Lindskog, S. and Hammarström, L. (1981) 
'Periodontal healing of exarticulated monkey teeth stored in milk or saliva', Scandinavian journal of dental research, 89(3), pp. 251-259.

Chandukutty, D. et al. (2017) 'Awareness of Dental Trauma Management among School Teachers of Kannur, Kerala, India', Journal of clinical and diagnostic research: JCDR, 11(2), pp. ZC08-ZC12.

Govindaraju, L., Jeevanandan, G. and Subramanian, E. M. G. (2017a) 'Comparison of quality of obturation and instrumentation time using hand files and two rotary file systems in primary molars: A single-blinded randomized controlled trial', European journal of dentistry, 11(3), pp. 376-379.

Govindaraju, L., Jeevanandan, G. and Subramanian, E. M. G. (2017b) 'Knowledge and practice of rotary instrumentation in primary teeth among indian dentists: A questionnaire survey', Journal of International Oral Health, 9(2), p. 45.

Jain, D., Dasar, P. L. and Nagarajappa, S. (2015) 'Natural products as storage media for avulsed tooth', Saudi Endodontic Journal. Medknow Publications and Media Pvt. Ltd., 5(2), p. 107.

Jeevanandan, G., Ganesh, S. and Arthilakshmi (2019) 'Kedo file system for root canal preparation in primary teeth', Indian journal of dental research: official publication of Indian Society for Dental Research, 30(4), pp. 622-624.

Jeevanandan, G. and Govindaraju, L. (2018) 'Clinical comparison of Kedo-S paediatric rotary files vs manual instrumentation for root canal preparation in primary molars: a double blinded randomised clinical trial', European archives of paediatric dentistry: official journal of the European Academy of Paediatric Dentistry, 19(4), pp. 273-278.

Juneja, P., Kulkarni, S. and Raje, S. (2018) 'Prevalence of traumatic dental injuries and their relation with predisposing factors among 8-15 years old school children of Indore city, India', Clujul medical (1957), 91(3), pp. 328-335.

Kumar, A. et al. (2011) 'Prevalence of traumatic dental injuries among 12- to 15-year-old schoolchildren in Ambala district, Haryana, India', Oral health \& preventive dentistry, 9(3), pp. 301-305.

Lieger, 0. et al. (2009) 'Impact of educational posters on the lay knowledge of school teachers regarding emergency management of dental injuries', Dental traumatology: official publication of International Association for Dental Traumatology, 25(4), pp. 406412.

Mathew, M. G. et al. (2020) 'A novel approach to regenerate bone loss in an adolescent using concentrated growth factors: One-year follow-up', Journal of Family Medicine and Primary Care. Wolters Kluwer--Medknow
Publications, 9(1), p. 428.

Mathew, M. G. et al. (2020) 'Evaluation of adhesion of Streptococcus mutans, plaque accumulation on zirconia and stainless steel crowns, and surrounding gingival inflammation in primary ...', Clinical oral investigations. Springer. Available at: https://link.springer.com/ article/10.1007/s00784-020-03204-9.

Mathew, M. G., Roopa, K. B. and Soni, A. J. (2020) 'Evaluation of clinical success, parental and child satisfaction of stainless steel crowns and zirconia crowns in primary molars', Journal of Family. ncbi. nlm.nih.gov. Available at: https://www.ncbi.nlm.nih. gov/pmc/articles/PMC7266243/.

Mathew, M. G. and Soni, A. J. (2019) 'Prevalence of three-rooted primary mandibular first molars in Karnataka (South Indian) population', International Journal of Pedodontic Rehabilitation. Medknow Publications and Media Pvt. Ltd., 4(1), p. 6.

Mohandas, U. and Chandan, G. D. (2009) 'Knowledge, attitude and practice in emergency management of dental injury among physical education teachers: a survey in Bangalore urban schools', Journal of the Indian Society of Pedodontics and Preventive Dentistry, 27(4), pp. 242-248.

Nagaveni, N. B., Poornima, P. and Bajaj, M. (2019) 'Revascularization of a Nonvital, Immature Permanent Tooth Using Amniotic Membrane: A Novel Approach', Journal of Clinical .... ncbi.nlm.nih.gov. Available at: https://www.ncbi.nlm.nih.gov/pmc/articles/ PMC6749878/.

Nagaveni, N. B., Poornima, P. and Mathew, M. G. (2020) 'A Comparative Evaluation of Revascularization Done in Traumatized Immature, Necrotic Anterior Teeth with and without Platelet-rich Fibrin: A Case Report', Journal of Clinical .... ncbi.nlm.nih.gov. Available at: https:// www.ncbi.nlm.nih.gov/pmc/articles/PMC7299885/.

Nagaveni, N. B., Poornima, P. and Valsan, A. (2018) 'Prevalence of three-rooted primary mandibular second molars in Karnataka (South Indian) population', International Journal of. ijpedor.org. Available at: http://www.ijpedor.org/article.asp?issn=2468-8932;ye ar $=2018 ;$ volume $=3 ;$ issue $=1 ;$ spage $=33 ;$ epage $=35 ;$ aulas $\mathrm{t}=$ Nagaveni.

Nagaveni, N. B., Yadav, S. and Poornima, P. (2017) 'Volumetric evaluation of various obturation techniques in primary teeth using cone beam computed tomography-An in vitro study', Journal of Indian. jisppd.com. Available at: http://www.jisppd.com/article. asp?issn=0970-4388; year $=2017$; volume $=35$;issue $=3 ;$ sp age $=244$; epage $=248$; aulast=Nagaveni .

Nair, M. et al. (2018) 'Comparative evaluation of postoperative pain after pulpectomy with k-files, kedo-s files and mtwo files in deciduous molars -a randomized 
clinical trial', Brazilian Dental Science, 21(4), p. 411. Neena, I. E. et al. (2017) 'Management of maxillary anterior supernumerary teeth', Astrocyte. astrocyte. in. Available at: http://www.astrocyte.in/article. asp? issn $=2349-0977$; year $=2017$; volume $=3$; issue $=4 ;$ sp age $=231$; epage $=233$; aulast $=$ Neena.

Panchal, V., Gurunathan, D. and Shanmugaavel, A. K. (2017) 'Smartphone application as an aid in determination of caries risk and prevention: A pilot study', European journal of dentistry, 11(4), pp. 469474.

Panchal, V., Jeevanandan, G. and Subramanian, E. (2019) 'Comparison of instrumentation time and obturation quality between hand $\mathrm{K}$-file, H-files, and rotary Kedo-S in root canal treatment of primary teeth: A randomized controlled trial', Journal of the Indian Society of Pedodontics and Preventive Dentistry, 37(1), pp. 75-79.

Panchal, V., Jeevanandan, G. and Subramanian, E. M. G. (2019) 'Comparison of post-operative pain after root canal instrumentation with hand $\mathrm{K}$-files, H-files and rotary Kedo-S files in primary teeth: a randomised clinical trial', European archives of paediatric dentistry: official journal of the European Academy of Paediatric Dentistry, 20(5), pp. 467-472.

Pani, S. C. et al. (2014) 'Knowledge and attitude of Saudi teachers of students with attention-deficit hyperactivity disorder towards traumatic dental injuries', Dental Traumatology, pp. 222-226. doi: 10.1111/edt.12065.

Ramadurai, N. et al. (2019) 'Effectiveness of 2\% Articaine as an anesthetic agent in children: randomized controlled trial', Clinical oral investigations, 23(9), pp. 3543-3550.

Ramakrishnan, M., Dhanalakshmi, R. and Subramanian, E. M. G. (2019) 'Survival rate of different fixed posterior space maintainers used in Paediatric Dentistry - A systematic review', The Saudi dental journal, 31(2), pp. 165-172.

Rao, A., Kommula, A. and Tummala, M. (2014) 'Delayed replantation after prolonged dry storage', Saudi Endodontic Journal. Medknow Publications and Media Pvt. Ltd., 4(2), p. 91.

Ravikumar, D. et al. (2018) 'DNA profiling of Streptococcus mutans in children with and without black tooth stains: A polymerase chain reaction analysis', Dental research journal, 15(5), p. 334.

Ravikumar, D. et al. (2019) 'Evaluation of McNamara's analysis in South Indian (Tamil Nadu) children between 8-12 years of age using lateral cephalograms', Journal of oral biology and craniofacial research, 9(2), pp. 193-197.

Ravikumar, D., Jeevanandan, G. and Subramanian, E. M. G. (2017) 'Evaluation of knowledge among general dentists in treatment of traumatic injuries in primary teeth: A cross-sectional questionnaire study', European journal of dentistry, 11(2), pp. 232-237.

Ravindra, V. et al. (2018) 'A comparative evaluation between dermatoglyphic patterns and different terminal planes in primary dentition', Journal of clinical and experimental dentistry, 10(12), pp. e1149-e1154.

Ravindra, V. et al. (2019) 'A comparative evaluation between cheiloscopic patterns and the permanent molar relationships to predict the future malocclusions', Journal of clinical and experimental dentistry, 11(6), pp. e553-e557.

Ravn, J. J. (1974) 'Dental injuries in Copenhagen schoolchildren, school years 1967--1972', Community dentistry and oral epidemiology. Wiley Online Library, 2(4), pp. 231-245.

Samuel, S. R., Acharya, S. and Rao, J. C. (2020) 'School Interventions-based Prevention of Early-Childhood Caries among 3-5-year-old children from very low socioeconomic status: Two-year randomized trial', Journal of public health dentistry, 80(1), pp. 51-60.

Subramanyam, D. et al. (2018) 'Comparative evaluation of salivary malondialdehyde levels as a marker of lipid peroxidation in early childhood caries', European journal of dentistry, 12(1), pp. 67-70.

Vignesh, R. et al. (2019) 'Management of Complicated Crown-Root Fracture by Extra-Oral Fragment Reattachment and Intentional Reimplantation with 2 Years Review', Contemporary clinical dentistry, 10(2), pp. 397-401.

Vishnu Prasad, S. et al. (2018) 'Report on oral health status and treatment needs of 5-15 years old children with sensory deficits in Chennai, India', Special care in dentistry: official publication of the American Association of Hospital Dentists, the Academy of Dentistry for the Handicapped, and the American Society for Geriatric Dentistry, 38(1), pp. 58-59. What are Flashcards and Why They Are a Good Tool for Mobile Learning? - Disprz (2018) Disprz. Available at: https://www.disprz.com/blog/flashcards-mobilelearning-tool/ (Accessed: 1 July 2020). 